\title{
Changing phenolic and proline content of Eclipta prostrata under impact of arbuscular mycorrhizal fungi and different sand/peat media
}

\author{
Imane HADDIDI - Au Trung VO - Katalin POSTA \\ Szent Istvan University, Institute of Genetics, Microbiology and Biotechnology. H-2100 Gödöllö,Hungary \\ E-mail: imane24haddidi@gmail.com; posta.katalin@mkk.szie.hu
}

Keywords: Arbuscular mycorrhizal fungi, Eclipta prostrata, Mycorrhizal inoculation, Sand, Peat

\section{Introduction}

Arbuscular mycorrhiza fungi (AMF) is one of the most important association existed and might have played important role in the colonization of the land. It was first coined by Frank (1885). A mycorrhiza is a symbiotic, non-pathogenic, permanent association between a plant root and specialized fungus both in natural environment and in cultivation. Mycorrhizal fungi may be involved in: improved uptake of macro and micronutrients, increased tolerance to stresses and beneficial alternations of plant growth regulators (PGRs). In earlier studies, AMF applied in the cultivation of medicinal plant have been undertaken to evaluate AMF efficiency and to quantify to change in both agronomic characteristic and pharmacology components. Eclipta prostrata is one of the main medicinal plants in Vietnam belonging to the family of Asteraceae and used for traditional medicine in Asian countries. However, the influence of different environment factors on the growth and biological component of E. prostrata are not tested until now. Therefore, the main goal of this study was to investigate the effect of AM inoculation and nutrient supply on the growth rate, total phenolic content, proline and root colonization of E. prostrata.

\section{Materials and methods}

Six proportions of sand and peat substrates were used, representing different nutrient supplies to test different growth parameters of E. prostrata. Sand and peat were evenly mixed and autoclaved before the experiment. The proportions of sand-peat were preparing in different proportions of $(0 / 100 \ldots . .100 / 0)(\mathrm{v} / \mathrm{v})$; The growing media (AMF+ plants) was mixed with $15 \mathrm{~g}$ of commercial AMF Symbivit ${ }^{\circledR}$ (a mixture of $G$. intraradices, $G$. mosseae, G. etunicatum, G. claroideum, G. microaggregatum, G. geosporum) which putted into the planting pots. And the control one contained the same proportion of sand and peat and mixed with $15 \mathrm{~g}$ Symbivit after have been sterilised. Seeds of Eclipta prostrata sterilised with $1 \% \mathrm{NaCl}$ then washed with sterilized water and seeding into the petri dish to generating. After seven days planting in the plastic pots. The plant is grown in a climatic chamber EKOCHL $1500\left(24 / 28^{\circ} \mathrm{C}, 60 \% \mathrm{RH}, 16 \mathrm{~h}\right.$ light $/ 8 \mathrm{~h}$ dark $)$ during seven to eight weeks. Each treatment had ten (10) biological replicates. Total phenolics (TP) concentration was measured by Folin-Ciocalteu assay and Proline content was quantified by reacting with acid ninhydrin,following the procedure of Bates 1973. Statistical analyzed was carried out using with ANOVA twoways test, and Tukey test was used as a posthoc test for multiple comparisons of the data measured. 


\section{Results and discussion}

After seven-week of growth, inoculation with a commercial product Symbivit (AMF+) promoted E. prostrata plants grown better than control- plants. Among the treatment AMF $+60: 40$ sand-peat showed the highest percentage of root colonisation $76.23 \pm 15.6 \%$ and the lowest one is 0:100 sand-peat $(23 \pm 4.72 \%)$

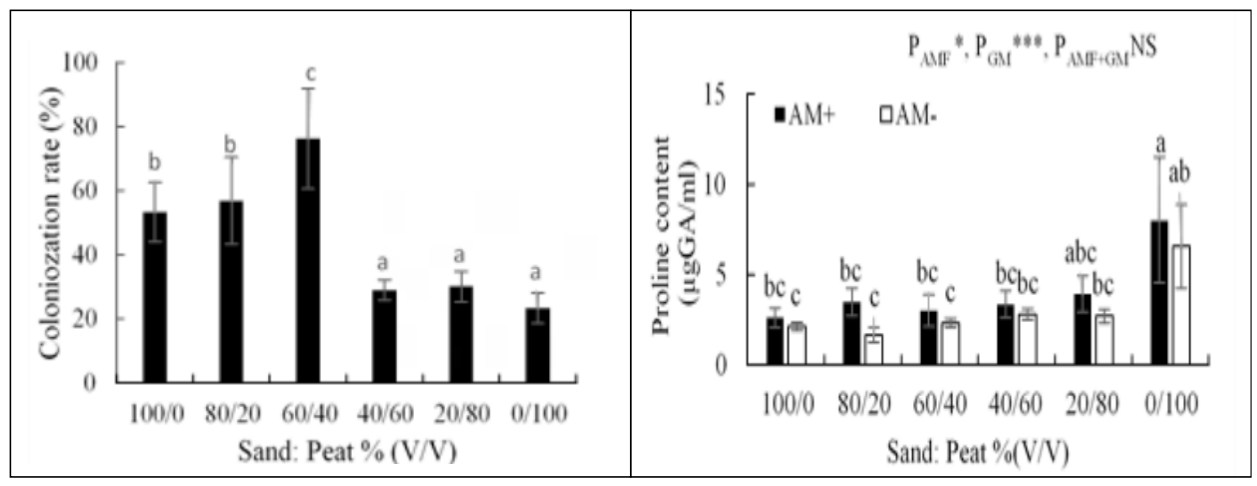

Figure 1: colonization rate

Figure 2: proline content

Different proportion of sand and peat with the inoculation of Symbivit ${ }^{\circledR}$ has a significant influence on proline concentration of the aerial part of Eclipta prostrata while proline concentration increase with the increase of peat proportion (100\% peat) in both treatment which is related with the higher effects on cell membranes stability and with higher Na content.

\section{Conclusions}

The experiment was indicated the best ratio of sand and peat to be expected for applying on a large scale with the purpose of commercial inocula development is $60 \%$ sand and $40 \%$ peat. - The result indicated more about using a commercial product with a diversity of Glomus spp apply for culture medicinal plant in the future.

\section{Acknowledgement}

This work was supported by Stipendium hungaricum scholarship.

\section{References}

Araim, G.; Saleem, A.; Arnason, J. T.; Charest, C. (2009): Root Colonization by an Arbuscular Mycorrhizal (AM) Fungus Increases Growth and Secondary Metabolism of Purple Coneflower, Echinacea Purpurea (L.) Moench. J. Agric. Food Chem., 57 (6), 2255-2258. https://doi.org/10.1021/jf803173x

Trouvelot, A., Kough, J., Gianinazzi-Pearson, V. (1986): Evaluation of VA Infection Levels in Root Systems. Physiol. Genet. Asp. Mycorrhizae. INRA Press. Paris, Fr.,217- 221. 